THE PUBLIC WELL-BEING-(continued)

\section{Protecting the Children.}

ON April 1 a number of important provisions of the Education Act came into force.

No child under twelve years of age may be employed at all.

No child between twelve and fourteen may be employed for more than two hours on Sunday or on school days, except after school hours and before 8 P.M., and on other days except between 6 A.M. and 8 p.x. Local authorities may pass by-laws permitting the employment of children on a school day before 9 o'clock in the morning, provided the employment is limited to one hour, and that the child so employed shall not be employed for more than one hour in the afternoon.

The hour after which child performers are not allowed to appear is altered from 9 p.M. to 8 P.M., and the permissible age from eleven to twelve. Licences will in future be within the discretion of the local education authority.

Section 18 provides for medical inspection and treatment of pupils in secondary and continuation schools.

By section 20 local authorities can ascertain what children in their areas are physically defective or epileptic, and the provisions of the Elementary Education Act (1914) relating to mentally defective children shall be extended to physically defective and epileptic children.

\section{A Health Chain.}

Another important step which has been taken is the issue of regulations by the Board of. Education (at the suggestion of Sir Robert Newman, Chief Medical Officer of the Ministry of Health), ensuring a medical record of all children passing from elementary to secondary schools. A child will thus have a complete medical record throughout the school life, and when the time comes for it to enter upon a career there will be a dossier of health for guidance. This continuous record is expected to be of great advantage from the standpoint of the individual, of public health, of medical observation and research, and of social reform. There have never before been such complete statistics as will now be collected. The school supervision, with ante-natal clinics, day nurseries, nursery schools, welfare centres, works welfare organisations, national health insurance, and so forth, are gradually building up a great national health chain from the cradle-even before that-to the workshop, and it is hoped that they will have a lasting effect on the health, happiness, and efficiency of coming generations.

\section{Regulating Employment of Children.}

Some sensible draft by-laws regarding child labour have been adopted by the Southport Education Committee, and endorsed by the Town Council. They provide that a child under fourteen shall not, among other things, be employed as a lather boy, or in a similar occupation in a barber's shop; in the kitchen of any hotel, cookshop, eating-house, or refreshment-room; as a marker or attendant in any billiard or bagatelle saloon or other place licensed for games; selling programmes, refreshments, or other articles, taking checks or tickets, or shifting scenery in any theatre, kinematograph hall, or other place of publio entertainment; in the collection or sorting of rags, old paper, or refuse; as attendant or assistant in an shop, hall, or other place used for public amusement b. means of automatic machines, mutoscopes, shooting range games of chance and skill, or similar devices, or in slaughterhouse.

A child between twelve and fourteen may be employe on school days between 5 and 7 р.м. (provided that a chil employed under a licence in a place of public entertai ment shall not have any other employment on the sam or following days), or on weekdays, when the school not open, for not more than five hours, not before 7 A. or after 7 P.M. ; and on Saturdays the child has to b free for not less than five hours continuously during the period.

A girl under sixteen or boy under fifteen will not b allowed to engage in street trading, and a boy unde sixteen only between 7 A.M. and 8 P.M. on weekdays, a not at all on a Sunday. A boy under sixteen so engage must not enter any premises licensed for public entertai ment or public-house for the purpose of trading or delive ing goods, and he must have a street trader's licence fro the education authority.

Boys and girls under sixteen must not trade at railway station entrance, and no licensed person, wh trading, may be assisted by an unlicensed person und sixteen.

Many of these by-laws indicate an understanding of the kinds of work which may be to the detriment of a child health, and, further, which cultivate a disagreeably pr cocious frame of mind or provide hectic experiences the child's moral and physical disadvantage.

\section{Venereal Disease.}

\section{Early Treatment Experiment in Manchester}

A Most useful-report on the first three months' wor of the Venereal Diseases Early Treatment Centre fo Males, in Great Bridgewater Street, Manchester, has be prepared by Dr. Young, assistant to the Medical Officet of Health. During that period there were 1,016 attend ances, 708 persons received treatment, and 117 wer referred to treatment clinics in the city. At first treat ment was given to all persons who had been exposed to infection within a day or two of appearing at the centre though they were at the same time informed that th treatment could not be relied upon under such conditions. But since January 5 no treatment has been given in cases where the interval between exposure and treatment was $^{\text {s }}$ twenty-four hours or over. Only one such case has been dealt with since that date, and he was referred to treatment clinic. It is now intended to limit the interval to twelve hours.

The experiment has proved (says the report) that met will not only come for early treatment, but will come within a reasonably short time after exposure to infec tion; that with the exception of two instances there have been no habitual frequenters; and that the centre is evidently a useful means of preventing the spread of venereal disease. The report recommends that, with the approval of the Ministry of Health, the centre should be allowed to continue in operation, and that another centre should be opened at the Victoria Street public convenience. The cost in Great Bridgewater Street has amounted to $2 \mathrm{~s}$. $0 \frac{1}{2} \mathrm{~d}$. per head, and 75 per cent. of the cost will be paid by the State. 